Ken Benson

Juan Carlos Cruz Suárez (eds.)

Territorios in(di)visibles

Dilemas en las literaturas hispánicas actuales 


\section{Ediciones de Iberoamericana}

Consejo editorial:

Mechthild Albert

Rheinische Friedrich-Wilhelms-Universität, Bonn

Daniel Escandell

Universidad de Salamanca

Enrique García-Santo Tomás

University of Michigan, Ann Arbor

Aníbal González

Yale University, New Haven

Klaus Meyer-Minnemann

Universität Hamburg

Daniel Nemrava

Palacky University, Olomouc

Emilio Peral Vega

Universidad Complutense de Madrid

Janett Reinstädler

Universität des Saarlandes, Saarbrücken

Roland Spiller

Johann Wolfgang Goethe-Universität, Frankfurt am Main 


\title{
Territorios in(di)visibles
}

Dilemas en las literaturas hispánicas actuales

\author{
Ken Benson \\ Juan Carlos Cruz Suárez (eds.)
}

Con la colaboración especial de Vicente Luis Mora 
Este libro se ha publicado gracias a la financiación concedida por el Fondo de Estudios Literarios como Área Superior de Investigación de la Facultad de Humanidades de la Universidad de Estocolmo (Litteraturvetenskap som ledande forskningsområde vid Humanistiska fakulteten, Stockholms universitet).

Cualquier forma de reproducción, distribución, comunicación pública o transformación de esta obra solo puede ser realizada con la autorización de sus titulares, salvo excepción prevista por la ley. Diríjase a CEDRO (Centro Español de Derechos Reprográficos) si necesita fotocopiar o escanear algún fragmento de esta obra (www.conlicencia.com;

$$
917021970 \text { / } 9327204 \text { 47). }
$$

\section{Derechos reservados}

(C) Iberoamericana, 2021

Amor de Dios, 1 - E-28014 Madrid

Tel.: +34914293522 - Fax: +34914295397

(C) Vervuert, 2021

Elisabethenstr. 3-9 - D-60594 Frankfurt am Main

Tel.: +49695974617 - Fax: +49695978743

info@iberoamericanalibros.com

www.iberoamericana-vervuert.es

ISBN 978-84-91922-18-6 (Iberoamericana)

ISBN 978-3-96869-183-1 (Vervuert)

ISBN 978-3-96869-184-8 (e-Book)

Depósito Legal: M-22011-2021

Diseño de la cubierta: a.f. Diseño y Comunicación

Impreso en España

Este libro está impreso íntegramente en papel ecológico sin cloro. 